\title{
Analysis of Micro-Morphology, Thermal Conductivity, Thermal Diffusivity and Specific Heat Capacity of Coconut Fibre Reinforced Foamed Concrete
}

\author{
M.A. Othuman Mydin ${ }^{1, a}$, N.A. Rozlan ${ }^{2}$, N. Md. Sani ${ }^{3}$, S. Ganesan ${ }^{4}$ \\ ${ }^{1,2,3,4}$ School of Housing, Building and Planning, Universiti Sains Malaysia, 11800, Penang, Malaysia
}

\begin{abstract}
With the quest for green construction and affordable housing systems for both rural and urban populations in Malaysia, various proposals focusing on cutting down on conventional building material costs have been put forward. One vanguard suggestion has been the sourcing, development and use of alternative, non-conventional local construction materials including the prospect of using some agricultural wastes as construction materials. This research describes experimental studies on the use of coconut coir fibre as an enhancer of foamed concrete with a focus on 2 parameters which are morphology properties and thermal properties of different percentages of coconut fibre $(0 \%, 0.2 \%$ and $0.4 \%)$. In this study the addition of coconut fibre significantly improved all the properties investigated. The results of the tests showed that the thermal properties of foamed concrete improved with an increase in the proportion of coconut fibre. Findings from this research will also be used to address the knowledge gap on the subject of foamed concrete and will provide an improved understanding and raised awareness of the potential for using waste materials for domestic construction.
\end{abstract}

\section{Introduction}

Specialists around the world have acknowledged the future need for construction materials that are light, durable, simple to use, economic and yet more environmentally sustainable. Some of the suggestions at the forefront have included the sourcing, development and use of alternative, nonconventional, and local construction materials as well as the prospect of using some agricultural wastes as construction materials. Natural reinforcing materials can be obtained at low costs and low levels of energy using local manpower and technology [1]. Utilization of natural fibres as a form of concrete enhancement is of particular interest to less developed regions where conventional construction materials are not readily available or are too expensive.

Lightweight foamed concrete has so far been used primarily as a filler material in civil engineering works. Nonetheless, it's good thermal and fire resistance indicates its strong potential as a material in building construction. It should be pointed out that foamed concrete made with Ordinary Portland Cement (OPC) has certain characteristics: it is good in terms of compression but very weak in terms of tension and tends to be brittle. The weakness in tension can be overcome by the use of conventional steel bar reinforcement and, to some extent, by the inclusion of a sufficient volume of

\footnotetext{
${ }^{\mathrm{a}}$ Corresponding author : azree@usm.my
} 
certain fibres. The use of fibres also alters the behaviour of the fibre-matrix composite after it has cracked, thereby improving its toughness [2].

Lightweight foamed concrete is not a new material in the construction industry. It was first patented in 1923 and a limited scale of production was instigated in the same year [3]. The use of foamed concrete was very limited until the late 1970s, when it started to be used in the Netherlands for ground engineering applications and void filling work. In 1987 a full-scale assessment of the application of foamed concrete as a trench reinstatement was carried out in the United Kingdom. The achievement of this trial led to the extensive application of foamed concrete for trench reinstatement and other applications then followed [4]. Since then, foamed concrete as a building material has become more widespread with expanding production and a wide range of applications [5].

This research serves as a preliminary study to characterize the thermal and micro-structural properties of foamed concrete with the inclusion of coconut fibre of different percentages. Fibres, which are at random dispersed throughout the foamed concrete, can overcome cracks and control shrinkage more efficiently. These materials have an exceptional combination of strength and energy absorption capacity. In general, the reinforcement from the fibres is not a substitution for conventional steel reinforcement, as the fibres and steel reinforcement both have their own roles in foamed concrete technology. Thus, there are many applications in which both fibres and continuous reinforcing steel bars can be used together. Nevertheless, fibres are not efficient in withstanding tensile stresses like conventional steel reinforcements can.

\section{Materials}

\subsection{Cement}

Ordinary Portland Cement (OPC) from Cement Industries of Malaysia Berhad (CIMA Group), labelled "Blue Lion," was used in this study. This type of cement is classified as MS 522, as well as BSEN 196. The product is available in 50 kilogram bags in bulk form. The fine inorganic material was used to form a paste after water was added into the mix [6].

\subsection{Fine Sand}

For this study, uncrushed fine aggregates were used in mortar mixes as a constituent material with a specific gravity of 2.83 and a maximum aggregate size of $5 \mathrm{~mm}$. The fine aggregates were graded in accordance to BS 812: Part 102 and the fitness moduli were determined to be 3.26 [7].

\subsection{Foam}

The protein foaming agent used, known as "NORAITE PA-1," was also manufactured in Malaysia [9]. The foaming agent was diluted in water with a ratio of 1:33 by water volume. The foam density needed to be between 75 to $80 \mathrm{~g} / \mathrm{L}$ before being mixed with other materials. Flow ability times were also calculated as the time was then used as a reference for adding the required amount of foam into the mix [10].

\subsection{Admixture}

In this study, natural coconut fibres were used. The fibres were cut to a length of $34 \mathrm{~mm}$ and different percentages of fibre volume, ranging from $0.2 \%$ to $0.4 \%$ by weight of total mix volume, were added to identify the strength of the foamed concrete [11].

\subsection{Water}

The water cement ratio was set to about 0.45 to achieve reasonable workability. In the case of foamed concrete, the added water needed to be carefully monitored to make sure the mixes were perfect [12]. 


\section{Experimental Setup and Mix Proportion}

\subsection{SEM Analysis Test}

Micro structural analysis (scanning electron microscopy) was used to determine the thickness and cross section of the fibres. This test was carried out at the Laboratory School of Biology and was done in order to get a better understanding of the bonding behaviour of the fibres. The samples were first placed in an oven to remove the water present in the pores and to dry. It was important to avoid penetration and polymerization of the epoxy. This test performed imaging in a high vacuum with the application of a conductive coating. The samples were made conductive with a carbon and gold layer. The accelerating voltage of the scanning electron microscope was $15 \mathrm{kV}$ [13]

\subsection{Thermal Test}

Thermal properties were investigated by using a hot disk thermal constant analyser. For thermal conductivity, heat is transported from high to low-temperature regions of a substance. The length of the samples was $70 \mathrm{~mm}$ with a thickness of $40 \mathrm{~mm}$ [14]. The test for each specimen was carried out over a period of about one day. Temperature and heat flow readings were taken at intervals of half an hour. All the data, such as thermal conductivity, thermal diffusivity and specific heat were recorded accordingly [15].

\subsection{Mixture Proportion}

Foamed concrete is produced through the mixture of cement, sand, water and stable foam. A ratio of 1:1.5:0.45 of cement, sand, and water, respectively, was used in this study. The water ratio used for the mix influenced the mixture which created a large volume of cement paste. Based on the experiment, the water requirement also depended upon the percentages and the additives used. The mixture of all materials needed to be blended well, as it could affect the outcome of the mix. The process of producing foamed concrete needs to be done over the course of a specific period of time. Typically, the best mixing time to get a good mix is between 15 to 20 minutes depending on the density of the foamed concrete, the mixer used and the weather conditions [16].

Depending on the temperature, a period of approximately 20 to 40 minutes of mixing was needed to get the reaction to complete. The properties of foamed concrete can be classified into fresh properties, physical properties, mechanical properties, durability and functional properties. Based on what was mentioned before, the properties of foamed concrete will be affected once the mixing process starts [17]. The foaming agent needed to be stable before being added into the mix. The reactions of the materials required awareness and proper supervision, as the hydration process began as soon as the mixing process started. It was important to control the mixing time, as an excessive mixing time would have broken the bubbles, affecting the foamed concrete's density [18]. After the foamed concrete was moulded and had set, it was wrapped with polyurethane sheets during the curing process. The foam generator used in this research, was a Portafoam TM2 System, made by a Malaysian manufacturer (www.portafoam.com).

\section{Results and Discussion}

\subsection{Scanning Electron Microscope (SEM) Analysis}

The SEM observations of the microstructure of three foamed concrete mixes with different percentages of CF are shown in Fig. 1. The percentages of CF affected the size of the pores produced. For the control foamed concrete, the pores formed were bigger compared to foamed concrete with the inclusion of CF. Coir fibres as additives reduced the amount and size of pores. On average, the pore size became smaller with an increase in mass density and compressive strength of comparable 
percentage. Coir fibre also helps in producing a more uniform distribution of the air voids. Thus, it will prevent bubbles from merging with each other and provide a uniform coating on each of the bubbles. Fig. 2 demonstrates the components of coir fibres which can be seen in the cement matrix.

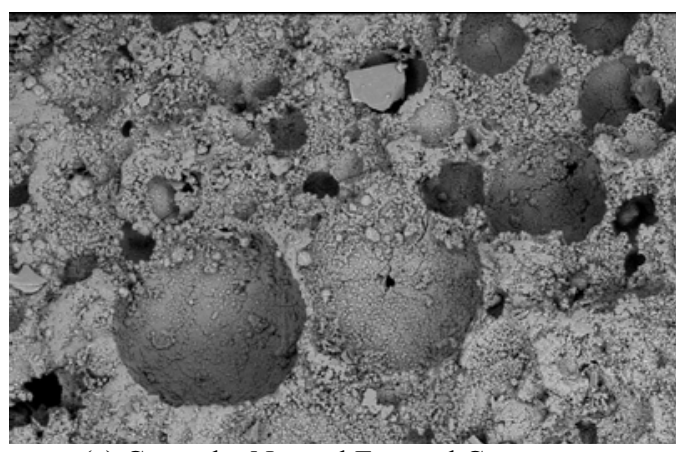

(a) Control - Normal Foamed Concrete

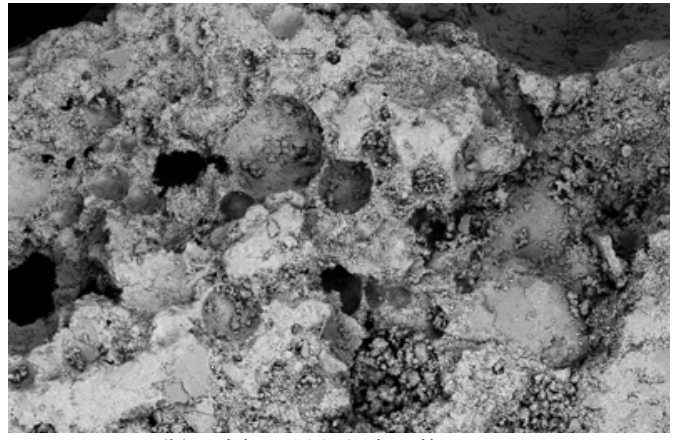

(b) with $0.2 \%$ Coir Fibre

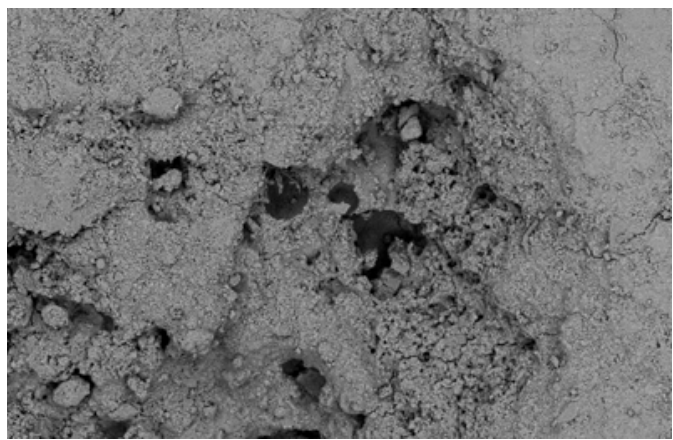

(b) With $0.4 \%$ Coir Fibre

Figure 1. Comparison of pore formation between normal foamed concrete (control) and foamed concrete with different percentages of coir at $1350 \mathrm{~kg} / \mathrm{m}^{3}$ density
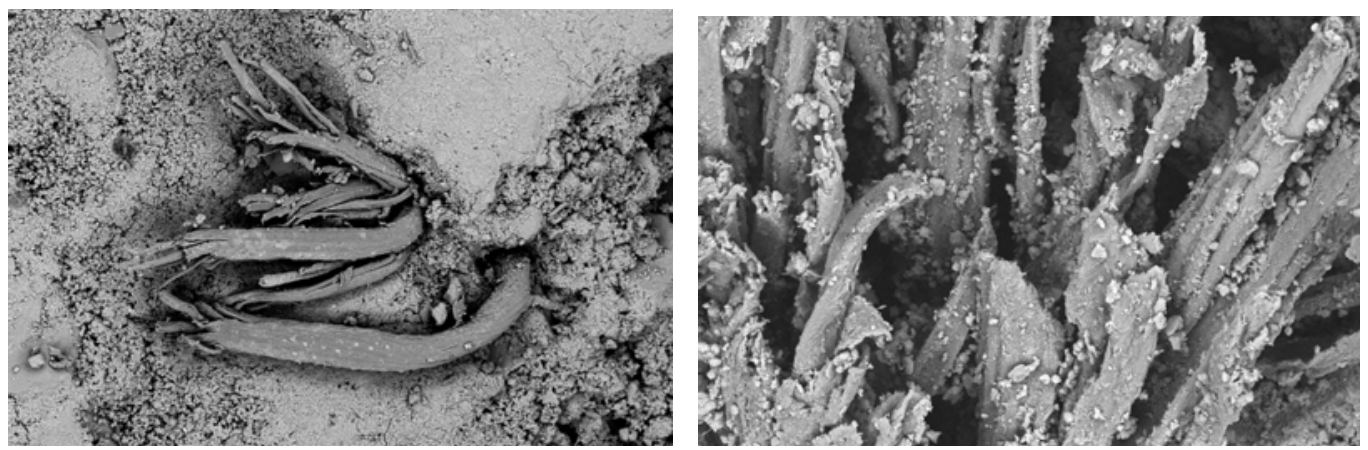

Figure 2. Components of coir fibres which can be seen in the cement matrix

\subsection{Thermal Properties}

\subsubsection{Thermal Conductivity}

The average thermal conductivity for all the samples is plotted in Fig. 3. Based on Fig. 3, it is clear that the control foamed concrete recorded the highest thermal conductivity of $0.57 \mathrm{~W} / \mathrm{mK}$. Comparing the foamed concrete with added CF to the control, the thermal conductivity decreased from $0.53 \mathrm{~W} / \mathrm{mK}$ to $0.48 \mathrm{~W} / \mathrm{mK}$. The results suggest that $0.4 \% \mathrm{CF}$ is well suited for thermal 
insulation applications since it has lower values of thermal conductivity compared to $0.2 \% \mathrm{CF}$ and the control. Ultimately, increasing the percentage of $\mathrm{CF}$ will reduce the thermal conductivity.

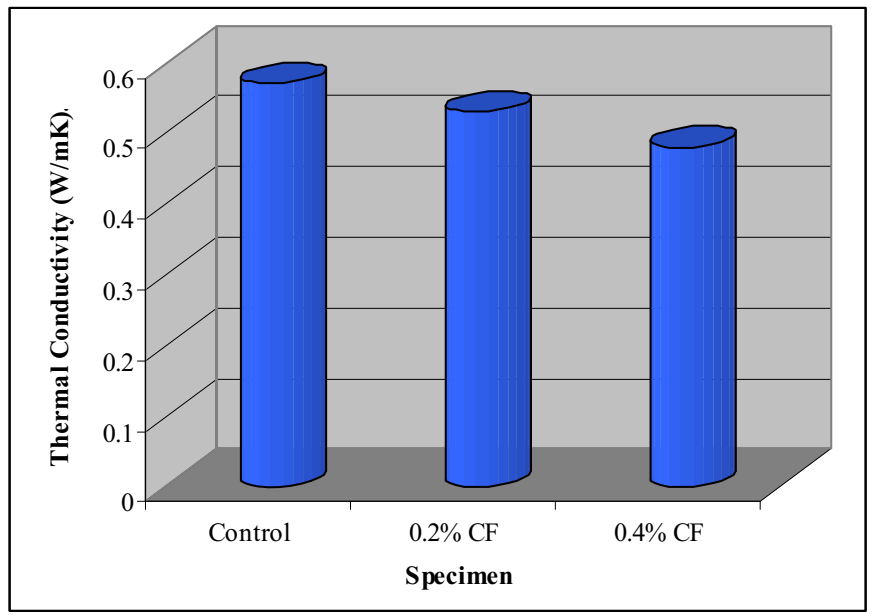

Figure 3. Comparison of thermal conductivity of foamed concrete with different CF percentages

\subsubsection{Thermal Diffusivity}

In heat transfer analysis, thermal diffusivity is the thermal conductivity divided by density and specific heat capacity at constant pressure. It measures the ability of a material to conduct thermal energy relative to its ability to store thermal energy. When the temperature increases, thermal diffusivity will decrease. Fig. 4 shows that the thermal diffusivity reduced $0.05 \mathrm{~mm} 2 / \mathrm{s}$ from $0.42 \mathrm{~mm}^{2} / \mathrm{s}$ to $0.37 \mathrm{~mm}^{2} / \mathrm{s}$, and then further reduced to $0.31 \mathrm{~mm}^{2} / \mathrm{s}$ for corresponding mix percentages of $0 \%$ (control), $0.2 \%$ and $0.4 \%$, respectively.

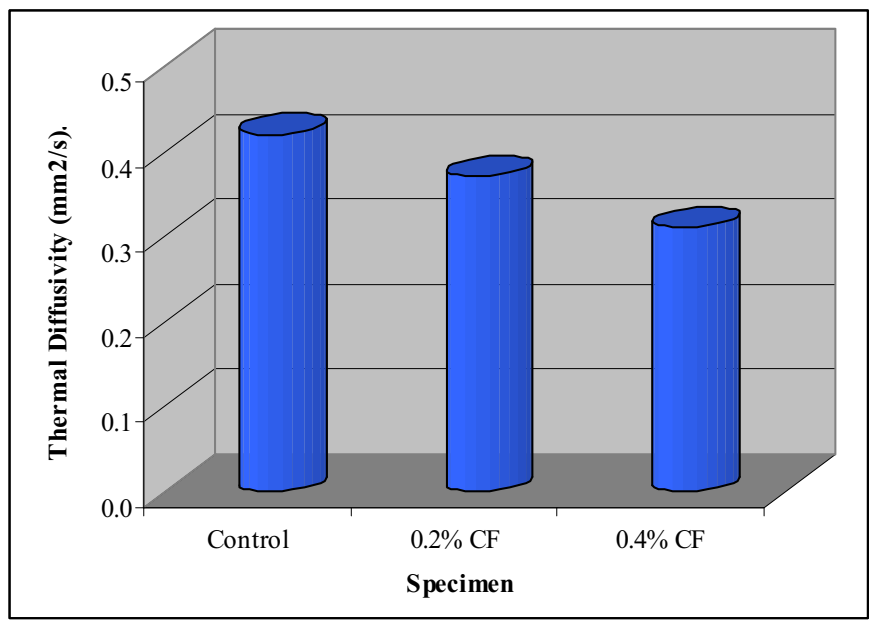

Figure 4. Comparison of thermal diffusivity of foamed concrete with different CF percentages

\subsubsection{Specific Heat}

Specific heat capacity is the quantity of heat required to raise the temperature of a substance by one degree Celsius. Units of Joules are frequently used to measure heat. The heat capacity of a substance can differ depending on what extensive variables are held constant, with the quantity being held constant usually denoted with a subscript. Fig. 5 shows the recorded specific heat of foamed concrete 
of different percentages of CF. It can be seen from Fig. 5 that the specific heat capacity of foamed concrete increased as the percentages of $\mathrm{CF}$ in the mix increased. For the control mix, the specific heat capacity was $1004 \mathrm{~J} / \mathrm{kg}^{\circ} \mathrm{C}$. With the addition of $0.2 \%$ of CF to the mix, it enhanced the specific heat capacity to $1057 \mathrm{~J} / \mathrm{kg}^{\circ} \mathrm{C}$. Meanwhile, the recorded specific heat for $0.4 \% \mathrm{CF}$ was $1135 \mathrm{~J} / \mathrm{kg}^{\circ} \mathrm{C}$.

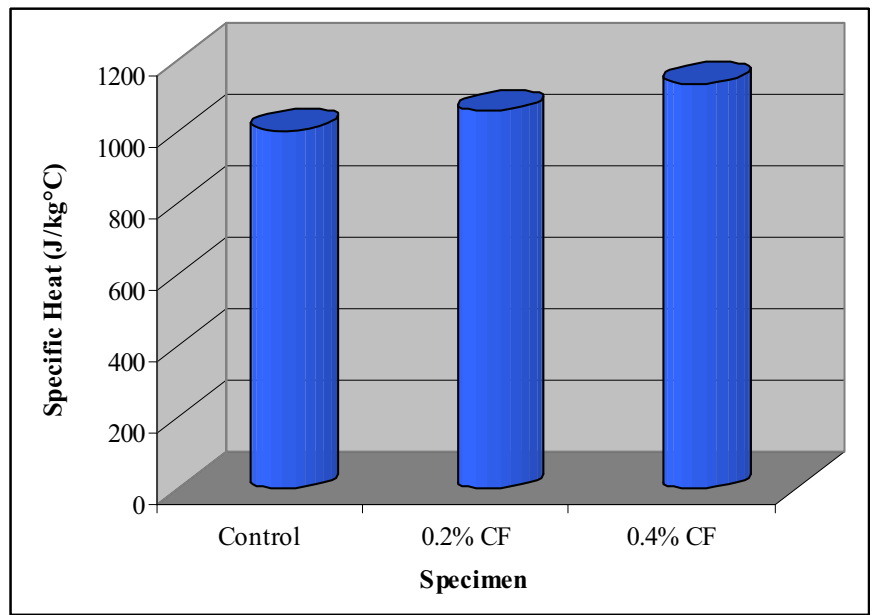

Figure 5.Comparison of specific heat of foamed concrete with different $\mathrm{CF}$ percentages

\section{Conclusion}

The results from the experimental investigations of the potential of coconut coir fibre in lightweight foamed concrete for the improvement of micro-structural and thermal properties were reported in this study. It was found that the addition of coir fibre significantly improved the thermal properties of the foamed concrete with different percentages demonstrating different thermal properties. Overall, the addition of coconut fibre improved the thermal conductivity, thermal diffusivity and specific heat capacity of the concrete. It can therefore be concluded that coconut fibres have the potential to be used in composites for different purposes. Since the use of coconut fibres has already led to the development of some excellent products, there remains the possibility of the invention of more new and improved products containing coconut fibres. However, before coconut fibre reinforced concrete can be used in main structural components like beams and columns, further investigation on its behaviour and properties is needed.

\section{Acknowledgement}

The authors would like to thank the funding bodies of this research; Universiti Sains Malaysia under USM Short Term Grant. No. 304/PPBGN/6312147

\section{References}

1. Othuman Mydin, M.A., Y.C. Wang, 2012. Mechanical properties of foamed concrete exposed to high temperatures. Journal of Construction and Building Materials, 26 (1): 638-654

2. Rao, K. M. M., and Rao, K. M. 2007. Extraction and tensile properties of natural fibers: Vakka, date and bamboo. Composite Structures, 77 (3): 288-295

3. Kessler, H. G. 1998. Cellular lightweight concrete, Concrete Engineering International, p 56-60.

4. Othuman Mydin, M.A., Y.C. Wang, 2011. Elevated-Temperature Thermal Properties of Lightweight Foamed Concrete. Journal of Construction \& Building Materials, 25 (2): 705-716 
5. Soleimanzadeh, S., M.A. Othuman Mydin, 2013. Influence of High Temperatures on Flexural Strength of Foamed Concrete Containing Fly Ash and Polypropylene Fiber, International Journal of Engineering, 26 (1): 365-374.

6. Othuman Mydin, M.A., 2011. Thin-walled steel enclosed lightweight foamcrete: A novel approach to fabricate sandwich composite. Australian Journal of Basic and Applied Sciences, $\mathbf{5}$ (12): 1727-1733

7. Othuman Mydin, M.A., Y.C. Wang, 2011. Structural Performance of Lightweight Steel-Foamed Concrete-Steel Composite Walling System under Compression. Journal of Thin-walled Structures, 49 (1): 66-76

8. BCA, 1994. Foamed concrete: Composition and properties. Report Ref. 46.042, Slough: BCA

9. Othuman Mydin, M.A., 2013. Modeling of Transient Heat Transfer in Foamed Concrete Slab. Journal of Engineering Science and Technology, 8 (3): 331-349

10. Aldridge, D., Ansell, T. 2001. Foamed concrete: production and equipment design, properties, applications and potential. In: Proceedings of one day seminar on foamed concrete: Properties, applications and latest technological developments, Loughborough University, p 1-7

11. Othuman Mydin, M.A., 2013. An Experimental Investigation on Thermal Conductivity of Lightweight Foamcrete for Thermal Insulation. Jurnal Teknologi, 63 (1): 43-49.

12. Othuman Mydin, M.A., 2013. Modeling of Transient Heat Transfer in Foamed Concrete Slab. Journal of Engineering Science and Technology, 8 (3): 331-349.

13. John, V. M., Cincotto, M. A., Sjostrom, C., Agopyan, V., and Oliveira, C. T. A., 2005. Durability of slag mortar reinforced with coconut fibre. Cement and Concrete Composites, 27 (5): $565-574$

14. Das Gupta, N. C., Paramsivam, P, and Lee, S. L., 1978. Mechanical properties of coir reinforced cement pastes composites. Housing Science, Pergamon Press Inc. London. 2 (5): 391-406

15. Slate, F. O., 1976. Coconut Fibers In Concrete. Eng J Singapore, 3 (1): 51-54.

16. Li, Z., Wang, L., and Wang, X., 2006. Flexural characteristics of coir fiber reinforced cementitious composites. Fibers and Polymers. 7 (3): 286-294.

17. Mydin, M.A., Y.C. Wang, 2012. Thermal and mechanical properties of Lightweight Foamed Concrete (LFC) at elevated temperatures. Magazine of Concrete Research, 64 (3): 213-224

18. Jones, M. R. \& McCarthy, 2006. A. Heat of hydration in foamed concrete: Effect of mix constituents and plastic density. Cement and Concrete Research, 36 (6): p 1032-1041. 